\title{
Sistem Pendukung Keputusan Pemberian Bantuan Dana Miskin pada Kabupaten Karo Menggunakan Metode AHP
}

\author{
${ }^{1)}$ Chandra Colia \\ UNIKA ST. Thomas SU, Jl. Setiabudi No 479 F Tanjungsari, Medan, Sumatera Utara, Indonesia, \\ Email : Chandrasemicol@gmail.com \\ 2)Lamhot Sitorus \\ UNIKA ST. Thomas SU, Jl. Setiabudi No 479 F Tanjungsari, Medan, Sumatera Utara, Indonesia, \\ Email : lamhot68@yahoo.com
}

\begin{abstract}
The Family Hope Program (PKH) is intended to build a system of protection for the poor. In $\mathrm{PKH}$, assistance given to very poor households is then obliged to send their children to school, conduct health checks including nutritional checks and immunization for toddlers and check the womb for pregnant women. In the short term, this assistance is expected to help reduce the burden of expenditure, while the long term is expected to break the chain of poverty between generations. Example: Jamkesmas, Apras (Pre-School Children, Toddler Children) The implementation of PKH carried out also by the Social Service Office in Karo Regency is still inadequate to provide assistance for poor funds, so that the system will be built using the AHP method. process or enter each specified condition or criteria and the weight that has been determined for each criterion into the system easily and quickly and make the report faster.
\end{abstract}

Kata Kunci: Sistem Pendukung Keputusan,Metode AHP,Bantuan Dana Miskin.

\section{PENDAHULUAN}

Indonesia adalah sebuah negara yang penuh paradoks. Negara ini subur dan kekayaan alamnya melimpah, namun sebagian cukup besar rakyat tergolong miskin.Jumlah penduduk miskin (penduduk yang berada di bawah Garis Kemiskinan) pada bulan Maret 2006 sebesar 39,05 juta jiwa atau $17,75 \%$ dari total penduduk Indonesia (Berita Resmi Statistik 1 September 2006).Upaya-upaya untuk meningkatkan kesejahteraan rakyat Indonesia telah dilakukan sejak awal kemerdekaan dan terus berlanjut sampai sekarang,hampir semua departemen mempunyai program penanggulangan kemiskinan, dan dana yangtelah dikeluarkan pemerintah untuk pelaksanaan programprogram tersebut telah mencapai puluhan trilyun rupiah.

Salah satu program penanggulangan kemiskinan di perkotaan (P2KP) yang dikategorikan sebagai Program Kerja Mandiri (Self Employment Program). P2KP (Program Penanggulangan Kemiskinan di Perkotaan) merupakan program pemerintah yang secara substansi berupaya dalam penanggulangan kemiskinan melalui konsep memberdayakan masyarakat dan pelaku pembangunan lokal lainnya, termasuk Pemerintah Daerah dan kelompok peduli setempat,sehingga dapat terbangun gerakan kemandirigunaan kemiskinan dan pembangunan berkelanjutan, yang bertumpu pada nilai-nilai luhur dan prinsip prinsip universal. P2KP telah mengembangkan Sistem Informasi Manajemen yang merupakan salah satu bagian dari Sistem Informasi berbasis komputer yang baru dikembangkan dan dimanfaatkan. Sistem Informasi ini berfungsi untuk memberi dukungan informasi bagi tingkatan manajemen P2KP dalam menjalankan tugas dan fungsinya.Namun dalam berbagai kasus, informasi yang dihasilkan sistem ini masih memiliki banyak keterbatasan apabila dipakai dalam pengambilan keputusan yang spesifik dan bersifat mendesak. Disisi lain pengambilan keputusan kerap dihadapkan pada masalah utamadalam penentuan keputusan strategis yang sulit direalisasikan akibat persepsi yang heterogen, Sejalan dengan kepentingan masing-masing individu/kelompok yang terlibat dalam pengambilan keputusan. Untuk mengatasi persoalan tersebut dibutuhkan suatu Sistem Pendukung Keputusan yang efektif, yang mampu memberia Iternatif solusi dalam pengambilan keputusan dan tidak memisahkan antara manusia, sarana/prasarana dan sistem manajemen secara keseluruhan agar dapat mencapai tujuan bersama. Karenanya timbul pemikiran untuk merancang suatu sistem pemandu pengambilan keputusan terkomputerisasi untuk pengalokasian dana bantuan langsung 
masyarakat pada Program Penanggulangan Kemiskinan Perkotaan. Sistem tersebut diharapkan dapat membuat pekerjaan lebih efektif dan efisien. Sistem jugadiharapkan dapat memperbesar kemampuan pembuat keputusan, meningkatkan ketelitian, mempercepat proses, dan mengurangi kelalaian. Berdasarkan uraian yang telah dijelaskan di atas maka dapat diambil suatu rumusan masalah yaitu pembuatan alat bantu yang dapat mendukung pengambilan keputusan untuk penilaian kelayakan usulan bantuan dana miskin.

\section{METODOLOGI PENELITIAN}

2.1. Pengumpulan Informasi:

a. Studi Kepustakaan yaitu penelusuran informasi kepustakaan baik Sistem Pendukung Keputusan maupun tentang analisis kelayakan proyek secara umum.

b. Wawancara dan Observasi, mencari dan mengumpulkan data, dimana data-data yang ada relevansinya dengan penelitian ini.

c. Tahap Rancangan

Setelah memahami masalah dan mencari solusi serta memahami kebutuhan pengguna, tahap selanjutnya adalah mendesain sistem agar dapat berjalan dengan baik, dan diharapkan mengatasi masalah yang ada. Perancangan system pendukung keputusan dipisahkan menjadi beberapa sub sistem:

1. Perancangan Subsistem Model

Model dirumuskan sebagai fungsi yang menggambarkan hubungan antara itemitem yang bersesuaian dalam penentuan kelayakan pemberian dana.

2. Perancangan Subsistem Basis Data

Data yang akan digunakan dalam Sistem Pendukung Keputusan ini ditampung pada sebuah basis data yang dikelola oleh suatu system manajemen basis data.

3. Perancangan Sub sistem Dialog

Perancangan ini dimaksudkan untuk membuat sistem dialog yang akrab bagi pemakai dengan menyertakan paket informasi tertentu.

d. Tahap Implementasi

Tahap Implementasi system meliputi proses persiapan sistem, konversi sistem, pengujian system dan pengoperasian sistem.

e. Ujicoba

Uji coba sistem dilakukan untuk menguji apakah kemampuan perangkat lunak yang dibuat sesuai dengan rancangan, termasuk di dalamnya penggunaan model-model yang ada.

\subsection{Pengembangan Sistem}

a. Tahap Perencanaan

Proses dilaksanakan, meliputi kegiatan identifikasi masalah, tujuan dari sistem, dan menyusun studi kelayakan.

b. TahapAnalisis

Tahapan selanjutnya adalah menganalisa permasalahan dan mencari solusi serta rencana-rencana dalam membangun Sistem Pendukung Keputusan.

\section{LANDASAN TEORI}

\subsection{Pengertian Sistem}

Sistem diartikan sebagai suatu kumpulan atau himpunan dari unsur, komponen, atau variable yang terorganisasi, saling berinteraksi, saling tergantung satu sama lain dan terpadu. Teori sistem melahirkan konsepkonsep futuristik, antara lain yang terkenal adalah konsep sibernitika (cybernetics). Konsep atau bidang kajian ilmiah ini terutama berkaitan dengan upaya-upaya untuk menerapkan berbagai disiplin ilmu, yaitu ilmu perilaku, fisika, biologi, dan teknik. (Tata Sutabri, 2012:3).

Sistem adalah sekumpulan elemen yang saling terkait atau terpadu yang dimaksudkan untuk mencapai suatu tujuan.Sebagai gambaran, jika dalam sebuah sistem terdapat elemen yang tidak memberikan manfaat, maka elemen tersebut dapat dipastikan bukanlah elemen dari suatu sistem. Jadi dari pengertian diatas sistem adalah suatu kesatuan yang terdiri dari bagian-bagian yang saling terintegrasi dan bekerja sama untuk mencapai sasaran tertentu.(Abdul Kadir ,2014 :61).

\subsection{Pengertian Informasi}

Informasi adalah data yang telah diklasifikasi atau diolah atau diinterpretasikan untuk digunakan dalam proses pengambilan keputusan. Sistem pengolah informasi akan mengolah datamenjadi informasi atau mengolah data dari bentuk tak berguna menjadi berguna bagi yang menerima. Nilai informasi berhubungan dengan keputusan. Bila tidak ada pilihan atau keputusan maka informasi tidak diperlukan. Keputusan dapat berkisar dari keputusan berulang sederhana sampai keputusan strategi jangka panjang. Nilai informasi paling penting berarti konteks pengambilan keputusan. (Tata Sutabri, 2012:21).

Informasi merupakan proses lebih lanjut dari data yang sudah memiliki nilai tambah. informasi dapat dikelompokkan menjadi 3 bagian, yaitu:

a. Informasi strategis. Informasi ini digunakan untuk mengambil keputusan jangka panjang, yang mencakup informasi 
eksternal, rencana perluasan perusahaandan sebagainya.

b. Informasi taktis. Informasi ini dibutuhkan untuk mengambil keputusan jangka menengah, seperti informasi tren penjualan yang dapat dimanfaatkan untuk menyusun rencana penjualan.

c. Informasi Teknis. Informasi ini dibutuhkan untuk keperluan operasional sehari-hari, seperti persedian stock, retur penjualan, dan laporan kas harian.

\subsection{Pengertian Sistem Pendukung Keputusan}

Sistem Pendukung Keputusan (SPK) atau Decision Support Systemadalah sistem informasi interaktif yang menyediakan informasi, pemodelan dan pemanipulasian data yang digunakan untuk membantu pengambilan keputusan pada situasi yang semiterstruktur dan situasi yang tidak terstruktur dimana tak seorang pun tahu secara pasti bagaimana seharusnya keputusan dibuat.(Abdul Kadir, 2012:53)[7].

Analytic Hierarchy Process (AHP) merupakan suatu metode analisis untuk struktur suatu masalah dan dipergunakan untuk mengambil keputusan atas suatu alternatif. AHP ini adalah suatu model yang luwes yang memberikan kesempatan bagi perorangan atau kelompok untuk membangun gagasan-gagasan dan mendefinisikan persoalan dengan cara membuat asumsi mereka masing-masing dan memperoleh pemecahan yang diinginkan darinya. AHP menunjukkan bagaimana menghubungkan kriteria-kriteria dari satu bagian masalah dengan kriteria-kriteria dari bagian lain untuk memperoleh hasil gabungan.Prosesnya adalah mengidentifikasi, memahami, dan menilai interaksi- interaksi dari suatu sistem sebagai satu keseluruhan (Endang Lestari 2009).

Sedangkan menurut Rosnani Ginting (2014 :8) Sistem Pendukung Keputusan (Decision Support System) merupakan suatu proses yang makin bersifat sistem tertutup, maka makin terstruktur, komputasi dan rutin serta merupakan keputusan yang dapat diambil dalam perencanaan dan pengendalian. Dengan kata lain, hasil keputusan ini dapat lebih siap didukung oleh proses komputerisasi

\subsection{Model Sistem Pendukung Keputusan}

a. Model Ikonicy yaitu: Menggambarkan simbol dari yang sebenarnya (sistem yang sebenarnya.Contoh: Prototype b. Model Analog yaitu: Menggambarkan hubungan fungsional daripada sistem .Contoh: Struktur Organisasi

c. Model Kuantitatif yaitu : Menggambarkan ruus-rumus matematika

Menurut Rosani Ginting (2012:25) tujuan sistem pendukung keputusan dibagi atas dua yaitu:

1. Mencoba menerapkan konsep Sistem Pendukung Keputusan dalam rangka membantu proses pengambilan keputusan.

2. Untuk membantu dalam mengantisipasi perubahan yang mungkin terjadi pada setiap pelaksanaan program kegiatan.

\subsection{Metode AHP (Analytic Hierarcy Process)}

Menurut Supriyono dkk (2007) metode AHP merupakan salah satu model untuk pengambilan keputusan yang dapat membantu kerangkaberfikir manusia. Metode ini dikembangkan oleh Thomas L Saaty pada tahun 1970 an. Dasar berfikirnya metode AHP ini adalah proses membentuk skor secara numerik untuk menyusun rangking setiap alternatif keputusan berbasis pada bagaimana sebaiknya alternatif itu dicocokkan dengan kriteria pembuat keputusan. Metode AHP ini membantu memecahkan persoalan yang kompleks dengan menstruktur suatu hirarki kriteria, pihak yang berkepentingan, hasil dan dengan menarik berbagai pertimbangan guna mengembangkan bobot atau prioritas. Metode merupakan penggabungan antara kekuatan dari perasaan dan logika yang bersangkutan pada berbagai persoalan.lalu mensintesis berbagai pertimbangan yang beragam menjadi hasil yang cocok dengan perkiran, secara intuitif pada pertimbangan yang telah dibuat, adapun strukturAHP yaitu:

1. Struktur yang berhirarki, sebagai konsekuensi dari kriteria yang dipilih, sampai pada Subkriteria yang paling dalam.

2. Memperhitungkan validitas sampai dengan batas toleransi inkonsistensi berbagai kriteria dan alternatif yang dipilih oleh pengambil keputusan. Memperhitungkan daya tahan outputanalisis sensitivitas pengambilan keputusan (Iskandar Z Nasibu,2009:3435)

\section{HASIL DAN PEMBAHASAN}

4.1. Data Flow Diagram (DFD) Level 0

DataFlow Diagram (DFD) mempunyai level atau tingkatan, level 0 merupakan diagram arus data yang mendasar dari sebuah proses, 
sedang level 1 dan seterusnya adalah merupakan pengembangan dari prosesproses yang ada pada level 0 yang bertujuan untuk lebih mudah dimengerti dan dipahami. Untuk lebih jelasnyaDataFlow Diagram (DFD) Level 0 pada sistem yang akan dibangun dapat dilihat pada Gambar 1. berikut

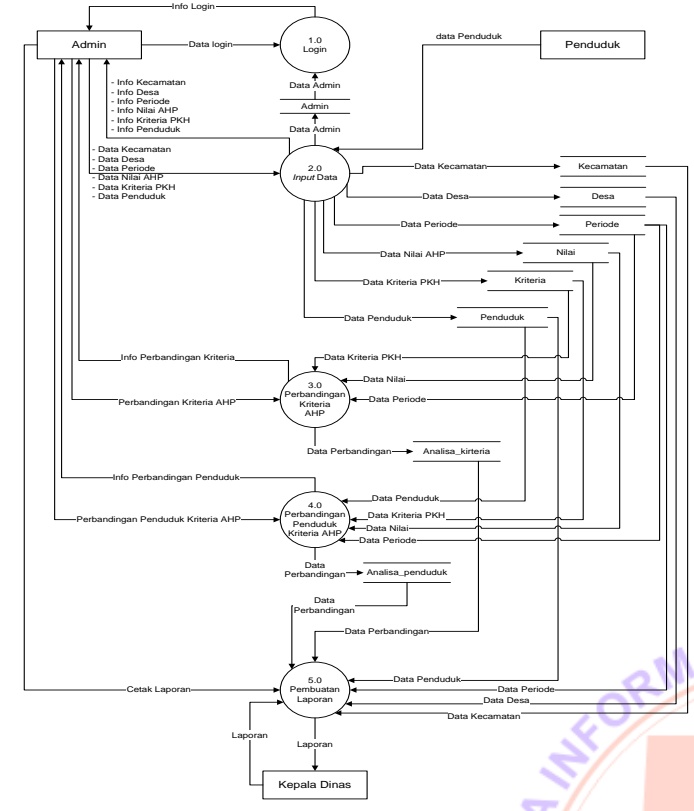

Gambar 1 Data Flow Diaram Level 0

\subsection{Data Flow Diagram Level 1 Proses 4}

Dari data flow diaram level 0 proses 4 di atas masih terdapat beberapa proses yang harus di pecah, dimana setelah admin selesai melakukan proses perbandingan kriteria dan perbandingan penduduk maka admin dapat memproses penilaian. Hubungan setiap proses dapat dilihat seperti pada Gambar 2 BERIKUT

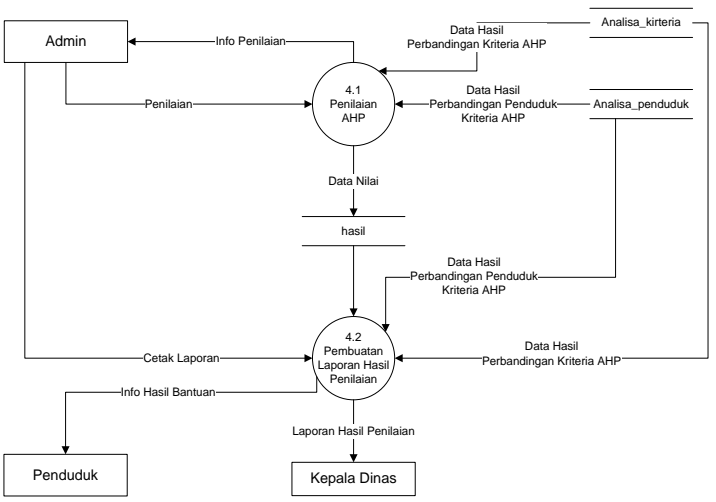

Gambar 2 Data Flow Diagram Level 1 Proses 4

\subsection{Halaman Login Admin}

Pertama kali program dijalankan maka yang tampil adalah halaman splashscreen dan halaman login untuk masuk kesistem. Jika pengguna benar memasukkan username dan password maka akan masuk ke sistem, jika tidak maka kesempatan hanya $3 \times$ melakukan login, jika salah sistem akan otomatis keluar. Tampilan Splash Screen pada Gambar 3 berikut

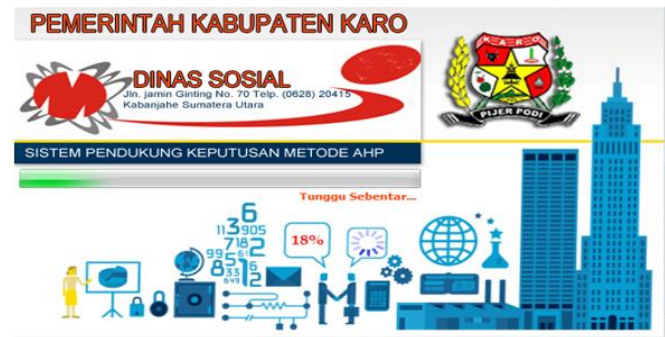

Gambar 3 Tampilan Halaman Splash Screen Sistem

\subsection{Login}

Halaman login admin berfungsi untuk mengolah data system dan hanya menginputkan data username dan password yang telah tersimpan dalam database dengan benar.Halaman login admin dapat dilihat seperti pada Gambar 4 berikut

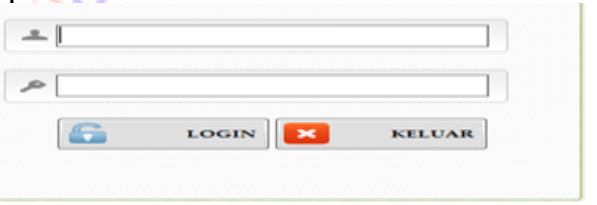

Gambar 4 Tampilan Halaman Login Admin

\subsection{Halaman Tampilan Utama}

Tampilan halaman utama akan menggambarkan bagaimana bentuk halaman utama pada sistem yang akan dibangun, dimana pada halaman utama terdapat menu yang dapat digunakan untuk memanggil form pengolahan data. Bentuk halaman utama dapat dilihat seperti pada Gambar 5. Berikut:

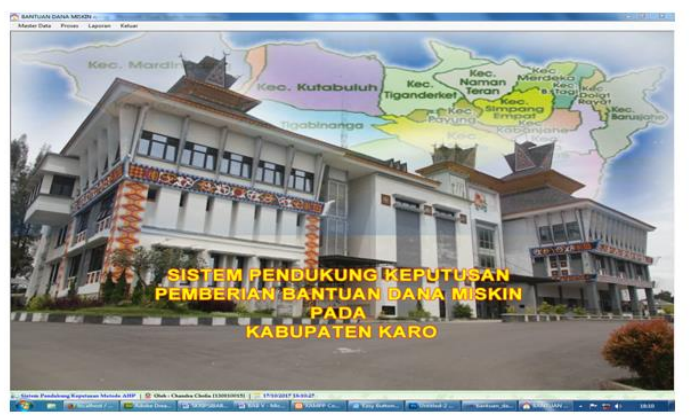

Gambar 5. Tampilan Halaman Utama

\subsection{Halaman Input Desa}

Tampilan halaman input desa akan menggambarkan bagaimana bentuk form penginputan data desa. Form input desa digunakan untuk mengolah data desa. Bentuk 
halaman input desa dapat dilihat seperti pada Gambar 6 berikut.

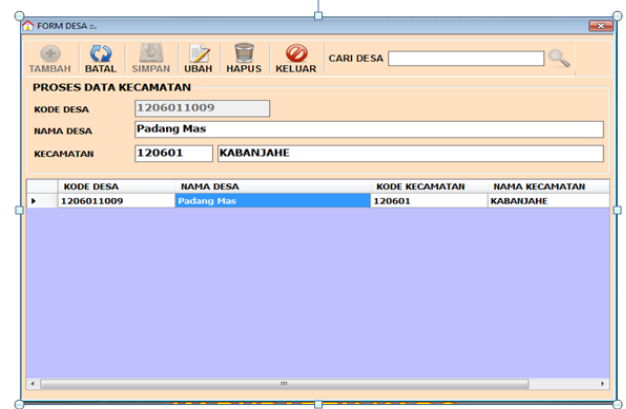

Gambar.6 Tampilan Halaman Input Desa

\subsection{Halaman Input Nilai AHP}

Tampilan halaman input nilai ahp akan menggambarkan bagaimana bentuk form penginputan data nilai ahp. Form input nilai ahp digunakan untuk mengolah data nilai ahp. Bentuk halaman input nilai ahp dapat dilihat seperti pada Gambar 7.

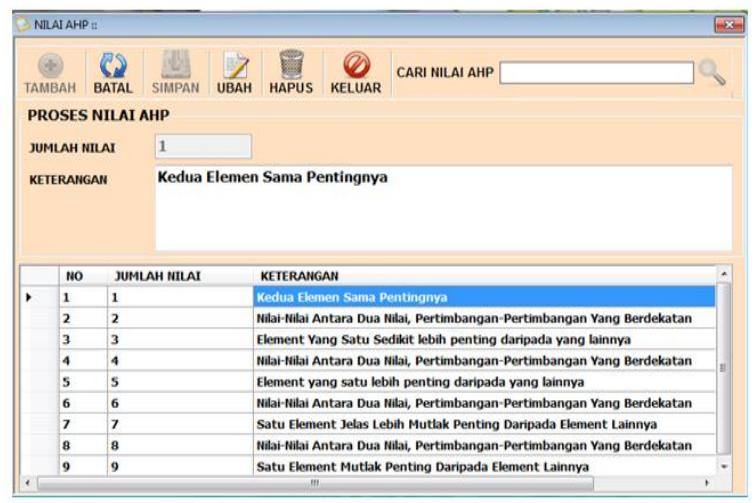

Gambar 7 Tampilan Halaman Input Nilai AHP

\section{KESIMPULAN}

Sistem pendukung keputusan penerimaan bantuan dana miskin dengan metode AHP dapat dijadikan sebagai salah satu solusi dalam menyelesaikan permasalahan pemberian bantuan dana miskin yang tepat sasaran. Dengan menerapkan kriteria yang sesuai dengan standar pemerintah di Indonesia, proses pemberian bantuan dana miskin bisa dilakukan dengan lebih akurat dan tepat dibanding dengan cara perhitungan manual. Kesimpulan yang didapat pada tugas akhir ini adalah sebagai berikut :

1. Dengan Hasil perhitungan dengan metode AHP akan lebih akurat dan lebih teliti daripada perhitungan manual jika dibandingkan terhadap hasil/fakta lapangan

2. Dengan adanya sistem pendukung keputusan ini maka penerima bantuan dana miskin akan jatuh ke tangan penduduk yang lebih tepat dan pasti.

\section{DAFTAR PUSTAKA}

[1]. Alter. Sistem Pendukung Keputusan (Decision Support System (DSS),Yogyakarta: CV.ANDI OFFSET,2014.

[2]. Supriyono dkk. 2007. "Analytic Hierarchy Process (AHP)". Journal Seminar Nasional

[3]. Fathansyah. 2012. Basis Data. Bandung : Penerbit Informatika

[4]. Pedoman Pelaksanaan Bimbingan Teknis Penerima KUBE Berkelanjutan PKH.2014.Sumatera Utara:Kementrian Sosial RI.

[5]. Iskandar Z Nasibu (2009). "Theory AHP (Analytic Hierarchy Process) and used decision support system". Journal Pelangi Ilmu Volume 2, 34-35

[6]. Buku Kerja Pendamping dan Operator PKH.2015.Sumatera Utara:Kementrian Sosial RI.

[7]. Tonni Limbong (2013). Implementasi Metode Simple Additive Weighting (SAW) Untuk Pemilihan Pekerjaan Bidang Informatika, STMIK Budi Darma

[8]. Tata Sutabri. Analisis Sistem informasi, Yogyakarta: CV.ANDI OFFSET,2014.

[9]. Rosnani Ginting. Sistem Pendukung Keputusan, Medan: USU Press,2014

[10]. Lia Rochmasari dkk.2010."Penetuan Prioritas Usulan Sertifikasi Guru Dengan Metode AHP". Jurnal Teknologi Informasi Volume 6,6.

[11]. Lamhot Sitorus, 2015. Algoritma Dan Pemrograman, Andi Offset, Yogyakarta. 